\title{
LETTERS
}

\section{Inappropriate Medication in Home Health Care}

\author{
Denys T. Lau, PhD' and Lisa L. Dwyer, MPH² \\ ${ }^{1}$ College of Pharmacy, University of Illinois-Chicago, Chicago, IL, USA; ${ }^{2}$ Centers for Disease Control and Prevention, National Center for Health \\ Statistics, Long-Term Care Statistics Branch, Hyattsville, MD, USA.
}

J Gen Intern Med 27(5):490

DOI: $10.1007 / \mathrm{s} 11606-012-1992-\mathrm{x}$

(C) Society of General Internal Medicine 2012

To the Editor: We read with interest the study by Bao and colleagues examining the use of Beers-defined potentially inappropriate medications among older patients receiving home health care (HHC) services in the United States. ${ }^{1}$ Ensuring proper medication use especially in older adults remains a public health priority, and the authors argue that HHC patients may be at high risk for using ineffective or unsafe medications likely due to their often complex medication regimens and multiple physician prescribers. The study analyzes the 2007 National Home and Hospice Care Survey (NHHCS), a nationally representative survey of U.S. home health and hospice care agencies that collected data on current HHC patients and hospice care discharges. ${ }^{2}$ Bao and colleagues restricted their analysis to HHC patients who were age 65 or older and used at least one medication $(n=3,124)$. The authors, however, did not differentiate between patients receiving and patients not receiving end-of-life (EOL) care. According to NHHCS, we calculated that $15 \%$ (weighted) of HHC patients in their study had a medical prognosis indicating a six-month-or-less life expectancy and received "palliative, end of life, or terminal care instead of active or curative treatment."

It is important for the Bao et al. study to distinguish between HHC patients who did and who did not receive EOL care. While the 2003 Beers list is commonly used to define medications to avoid among older patients ${ }^{3}$ (albeit not without controversy), there is no clear consensus about which medications are unsuitable for older patients receiving EOL care. The validity of the Beers list as a prescribing quality indicator to assess EOL treatment is disputable in principle and evidence. ${ }^{4}$ Research has argued that shortacting benzodiazepines, gastrointestinal antispasmodics,

Published online January 31, 2012 anticholinergics, and antihistamines that are on the Beers list may be clinically appropriate for older patients receiving EOL care whose goal of care is to manage pain and other distressing symptoms. ${ }^{5}$ Furthermore, although long half-life benzodiazepines generally should be avoided in older patients according to Beers, withdrawing a long half-life benzodiazepine may pose unnecessary, significant risk for major withdrawal symptoms in older patients receiving EOL care. ${ }^{6}$ Consequently, the examination of inappropriate medication use among $\mathrm{HHC}$ patients without differentiating between those receiving and those not receiving EOL care raises concerns about the Bao et al. study findings and their suggested policy and practice implications. In general, applying the Beers list to examine medication appropriateness in older adults should be performed judiciously in settings where EOL care is provided.

Corresponding Author: Denys T. Lau, PhD; College of Pharmacy, University of Illinois-Chicago, $833 \mathrm{~S}$. Wood Street (m/c 871), Chicago, IL 60612, USA (e-mail: DTLau@uic.edu).

\section{REFERENCES}

1. Bao Y, Shao H, Bishop TF, Schackman BR, Bruce ML. Inappropriate medication in a National sample of US elderly patients receiving home health care. J Gen Intern Med. 2011 Oct 6. [Epub ahead of print].

2. National Center for Health Statistics. 2007 National Home and Hospice Care Survey and National Home Health Aide Survey, Survey Documentation. Hyattsville, MD: 2009.

3. Fick DM, Cooper JW, Wade WE, Waller JL, Maclean JR, Beers MH. Updating the beers criteria for potentially inappropriate medication use in older adults: results of a US consensus panel of experts. Arch Intern Med. 2003;163(22):2716-24.

4. Holmes HM, Hayley DC, Alexander CG, Sachs GA. Reconsidering medication appropriateness for patients late in life. Arch Intern Med. 2006;166(6):605-9.

5. Bain KT, Weschules DJ. Medication inappropriateness for older adults receiving hospice care: a pilot survey. Consult Pharm. 2007;22(11):926-34.

6. O'Mahony D, O'Connor MN. Pharmacotherapy at the end-of-life. Age Ageing. 2011;40(4):419-22. 